\title{
Impact of Inflammation on Cytochromes P450 Activity in Pediatrics: A Systematic Review
}

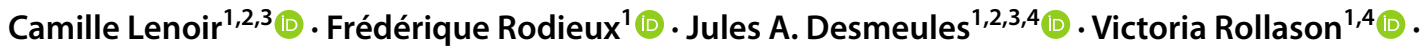 \\ Caroline F. Samer ${ }^{1,4}$ (B)
}

Accepted: 26 July 2021 / Published online: 31 August 2021

(c) The Author(s) 2021

\begin{abstract}
Background and Objective Cytochromes P450 (CYP) are the major enzymes involved in hepatic metabolism of drugs. Personalization of treatment in pediatrics is a major challenge, as it must not only take into account genetic, environmental, and physiological factors but also ontogeny. Published data in adults show that inflammation had an isoform-specific impact on CYP activities and we aimed to evaluate this impact in the pediatric population.

Methods Articles listed in PubMed through 7 January, 2021 that studied the impact of inflammation on CYP activities in pediatrics were included in this systematic review. Sources of inflammation, victim drugs (CYP involved), effect of drugdisease interactions, number and age of subjects, and study design were extracted.

Results Twenty-seven studies and case reports were included. The impact of inflammation on CYP activities appeared to be age dependent and isoform-specific, with some drug-disease interactions having significant pharmacokinetic and clinical impact. For example, midazolam clearance decreases by $70 \%$, while immunosuppressant and theophylline concentrations increase three-fold and two-fold with intensive care unit admission and infection. Cytochrome P450 activity appears to return to baseline level when the disease is resolved.

Conclusions Studies that have assessed the impact of inflammation on CYP activity are lacking in pediatrics, yet it is a major factor to consider to improve drug efficacy or safety. The scarce current data show that the impact of inflammation is isoform and age dependent. An effort must be made to improve the understanding of the impact of inflammation on CYP activities in children to better individualize treatment.
\end{abstract}

\section{Introduction}

Inflammation is a universal protective reaction to endogenous or exogenous aggression that involves all tissues and both innate and adaptive immunity. It is known to induce changes in the concentrations of many plasma proteins and

Caroline F. Samer

caroline.samer@hcuge.ch

1 Division of Clinical Pharmacology and Toxicology, Department of Anesthesiology, Pharmacology, Intensive Care, and Emergency Medicine, University Hospital of Geneva (HUG), Rue Gabrielle-Perret-Gentil 4, 1211 Geneva 14, Switzerland

2 Institute of Pharmaceutical Sciences of Western Switzerland (ISPSO), University of Geneva, Geneva, Switzerland

3 School of Pharmaceutical Sciences, University of Geneva, Geneva, Switzerland

4 Faculty of Medicine, University of Geneva, Geneva, Switzerland in several behavioral, physiological, and biochemical mechanisms [1]. Inflammation is complex and well orchestrated, as certain triggered mechanisms initiate, amplify, or sustain the process with many cell types and molecules [1]. Cytokines, and in particular interleukin-6, are the main stimulators of these acute changes [1]. Published data in adults indicate that inflammation has an impact on cytochromes P450 (CYP) activity, the major enzymes involved in drug metabolism, in an isoform-specific manner, and as a result of pre-transcriptional and post-transcriptional mechanisms that are cytokine specific [2-7]. Indeed, CYP activity is influenced by the interaction of genetic, environmental, and physiological factors through a wide variety of ligand-activated transcription factors and mediators regulating hepatic CYP content $[6,8]$. Understanding the impact of inflammation on CYP activity is important to understand in order to personalize drug use, as many diseases such as infection, cancer, diabetes mellitus, autoimmune disease, surgery, or trauma are associated with inflammation $[1,9,10]$. 


\section{Key Points}

The impact of inflammation on cytochrome P450 activities appears to be age dependent in the study population.

The impact of inflammation on cytochrome P450 activities appears to be isoform-specific.

Data that have evaluated the impact of inflammation on cytochrome $\mathrm{P} 450$ activities in pediatrics are lacking, as they frequently are in this particular population.

Children are not exempt from inflammation and inflammatory diseases, but data are scarce on the impact of inflammation on CYP activities and drug metabolism in the pediatric population [11]. It is well known that pediatric clinical trials are often lacking and less than half of labelled drugs have pediatric data [12]. Moral, ethical, and legal issues prevent rigorous scientific investigations in the pediatric population, and infant dosing regimens are often extrapolated based on data available only in the adult population [13]. However, children differ from adults in terms of height and weight but also in physiological perspectives because of an ontogeny [12]. The maturation and development of organs and enzyme systems influence the pharmacokinetics (PK) and pharmacodynamics of drugs, which may lead to potential variation in the efficacy and safety of drugs [13]. Ontogeny processes are complex and non-linear, making the pediatric population very heterogeneous and as such, the developmental course of all processes contributing to drug disposition cannot be described by a single uniform pattern $[14,15]$. However, differences in drug-metabolizing enzyme activity appear to be the main determinants of the overall pharmacokinetic differences observed between adults and children [16]. Cytochrome P450s are mostly present at birth but are immature [15]. The development of enzyme activity over time is isoform-specific and is rapidly improving in the first weeks/years of life [12, 15]. Although data are still sporadic and sometimes contradictory, it is generally recognized that CYP1A2 has the slowest developmental pattern [17-19]. CYP2C19 and CYP3A4 likely have an intermediate pattern, with an adult's activity reached at the end of infancy [17-19]. In contrast, CYP2B6, CYP2C9, and CYP2D6 activity increases rapidly during the first months of life and early infancy [17-19]. As with adults, the use of effective and safe therapy in children requires a good understanding of the inter-individual and intra-individual variability due to their growth and maturation, and ontogeny should be taken into account when selecting a drug dosage in children [15, 17, 20]. Many efforts have been made in recent decades to predict age-related alterations in the PK of drugs in children [14]. Modeling approaches, such as physiology-based PK, are increasingly used in order to obtain pediatric data including both growth and maturation processes (intrinsic characteristics) and drug-specific parameters (extrinsic parameters) $[16,21]$. They allow for safe and effective pediatric study designs and successful prediction of PK in the pediatric population [21]. Knowledge of the impact of disease and inflammation on CYP activity and drug PK appears to be an additional important element to consider. The aim of this systemic review was thus to evaluate the impact of inflammation on CYP activity in the pediatric population.

\section{Methods}

The Preferred Reporting Items for Systematic Review and Meta-Analyses (PRISMA) statement requirements and the PICOS framework were used to manage and to develop the current literature search, respectively [22]. The PICOS framework we used was as follows: participants: children with source of inflammation; intervention: victim drugs and CYP concerned; comparison: healthy children or before the onset of inflammation or receiving treatment for inflammation; outcomes: effect of the interaction between inflammation and CYP activity; design of the studies: clinical trials and case reports/series.

\subsection{Database and Search Strategy}

PubMed via MEDLINE, the database of biomedical publications, was used to carry out the literature search for studies and case reports/series until 7 January, 2021. We also completed our literature search with a manual search of references for potentially relevant articles. We used the keywords "Inflammation", "cytochrome P450", "cytochromes P450”, and "CYP450".

\subsection{Study Selection}

The following eligibility criteria were applied to select only pertinent publications from the literature search. Randomized controlled trials, non-randomized studies, and observational studies were the types of studies selected in our literature search, as well as case reports and series. Studies had to be published in English as full-text articles or congress abstracts, from database inception until 7 January, 2021. Studies participants had to be under 18 years of age, including healthy subjects and patients who suffered from inflammatory conditions caused by a disease, treatment, or a medical or surgical procedure. The outcomes of interest were the effect of potential (suggested or provided) inflammation on the metabolic ratios of CYP isoforms and the pharmacokinetic/pharmacodynamic and safety profiles of CYP substrates. 
The screening of publications was done in several steps. First, the titles of the articles were read to make an initial selection. Then, the abstract and full text were read successively to filter out potentially relevant articles according to the predefined eligibility criteria. The remaining articles were categorized into literature reviews, in vitro, animals, in silico, and human studies. Studies concerning adults were then removed, retaining only those publications that concerned pediatrics (defined as under 18 years of age). Finally, they were classified as studies or case reports/series. A similar process was applied to the additional articles found by a manual search. The study selection method was summarized in a flowchart created according to the PRISMA statement requirements (Fig. 1) [22].

\subsection{Data Extraction and Management}

The reference management software Zotero (Version 5.0.85, (c) 2006-2018 Contributors) was used to collect and export highlighted articles and then, to remove duplicates. Data from the included articles were extracted and synthetized, and the extracted data were classified according to age group, namely pediatrics (under 18 years) and adults (over 18 years). The authors extracted the data according to the PICOS framework previously discussed. As a reminder, these included study design, sample size, source of inflammation and comparators, victim drugs and CYP involved in their mechanism, and outcomes of interests (effect of drug-disease interactions). A check of the metabolite pathway of the victim drug was performed to confirm whether it was a CYP substrate and which CYP was involved. The Summary of Product Characteristics, the Lexi-Interact drug interaction checker, and the Geneva table of CYP substrates, inhibitors, and inducers were used to perform this verification process $[23,24]$.

\section{Results}

\subsection{Identification and Selection of the Studies}

The first step of the PubMed research led to a total of 2283 articles, and of these articles, 523 remained after screening by title and abstract. By cross-referencing and handsearching the reference list of relevant articles, 366 additional articles were added, resulting in 889 articles. Next, 128 records were not available in full text and 224 were not translated into English or considered irrelevant, leading to the deletion of 352 records. The remaining 537 articles were categorized into review articles $(n=55)$, in vitro $(n=77)$, or in-silico $(n=8)$ studies and studies conducted in animals $(n=152)$ or humans $(n=245)$. Only publications involving humans were included in the current systematic review and were classified as including adults $(n=218)$ or children $(n=27)$. Articles and case reports concerning the adult population are the subject of another systematic review. Finally, 27 articles conducted in pediatrics were included and classified as studies $(n=19)$ and case reports/series $(n=8)$ for analysis. These results are summarized in Fig. 1.

\subsection{Synthetized Findings}

Table 1 summarizes the cases of drug-disease interactions presented in the 27 eligible publications. The drug-disease interactions found in the selected publications were organized by victim drug and CYP involved in their metabolism. The most cited inflammation perpetrator was infection and the two most studied CYPs were CYP1A2 and CYP3A because many were receiving theophylline or immunosuppressants.

\section{Discussion}

Understanding the PK and the pharmacodynamics of drugs is the key element to accurately determining the safest and most effective dose of a prescribed drug in pediatrics [17]. In children, in addition to environmental, genetic, and individual factors, such as comorbidities and medications, the influence of ontogeny must be considered and complicates prediction of the response to a treatment [17, 20]. However, because of the lack of specific studies, pediatric data are almost exclusively extrapolated from adult studies [15].

One of the covariates known to contribute to dynamic changes in CYP activity in adults is inflammation [2-6]. Little is known about the effect of inflammation on CYP activity in pediatrics and, to our knowledge, there is only one review on the subject [11]. Very few studies have been published in almost 10 years. The consequences of inflammation on CYP activities appear to be different between adults and children and confirms the impossibility of simply extrapolating the adult data, as shown in the different studies included in this review.

\subsection{CYP3A4}

CYP3A4 was the most studied CYP in children, in particular, the impact of inflammation on tacrolimus and cyclosporin A (CyA) pharmacokinetic parameters was assessed. Tacrolimus and CyA blood concentrations increased after a diarrheal episode due to a bacterial or viral infection [38-41]. Despite a probable effect of diarrhea on absorption, the authors concluded that intestinal inflammation suppressed the activity of CYP3A [38]. Similarly, in adults, several studies and case reports have focused on the impact of hepatitis $\mathrm{C}$ infection on tacrolimus and $\mathrm{CyA}$ 


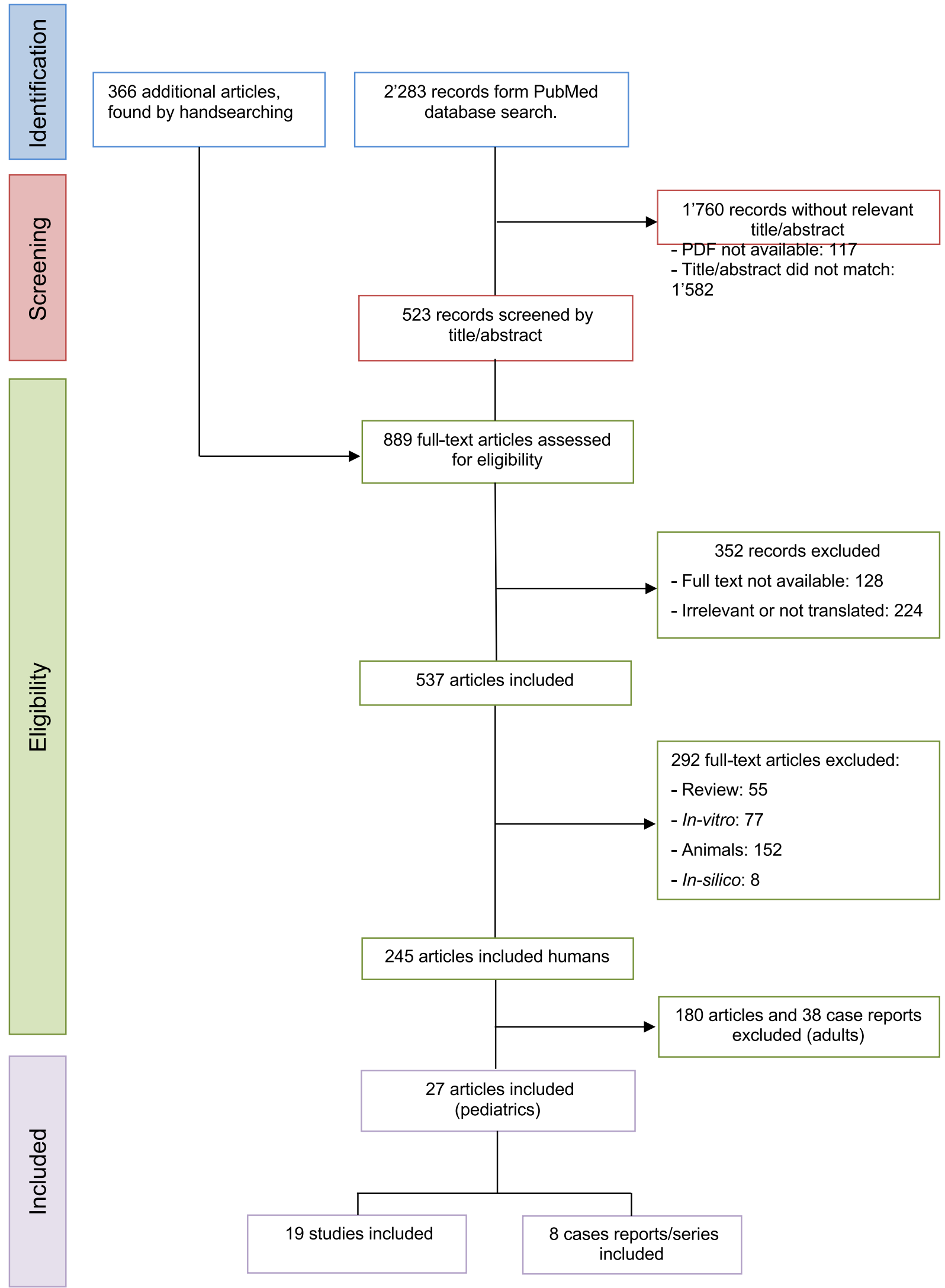

Fig. 1 Preferred Reporting Items for Systematic Review and Meta-Analyses (PRISMA) flowchart of the studies selection process 


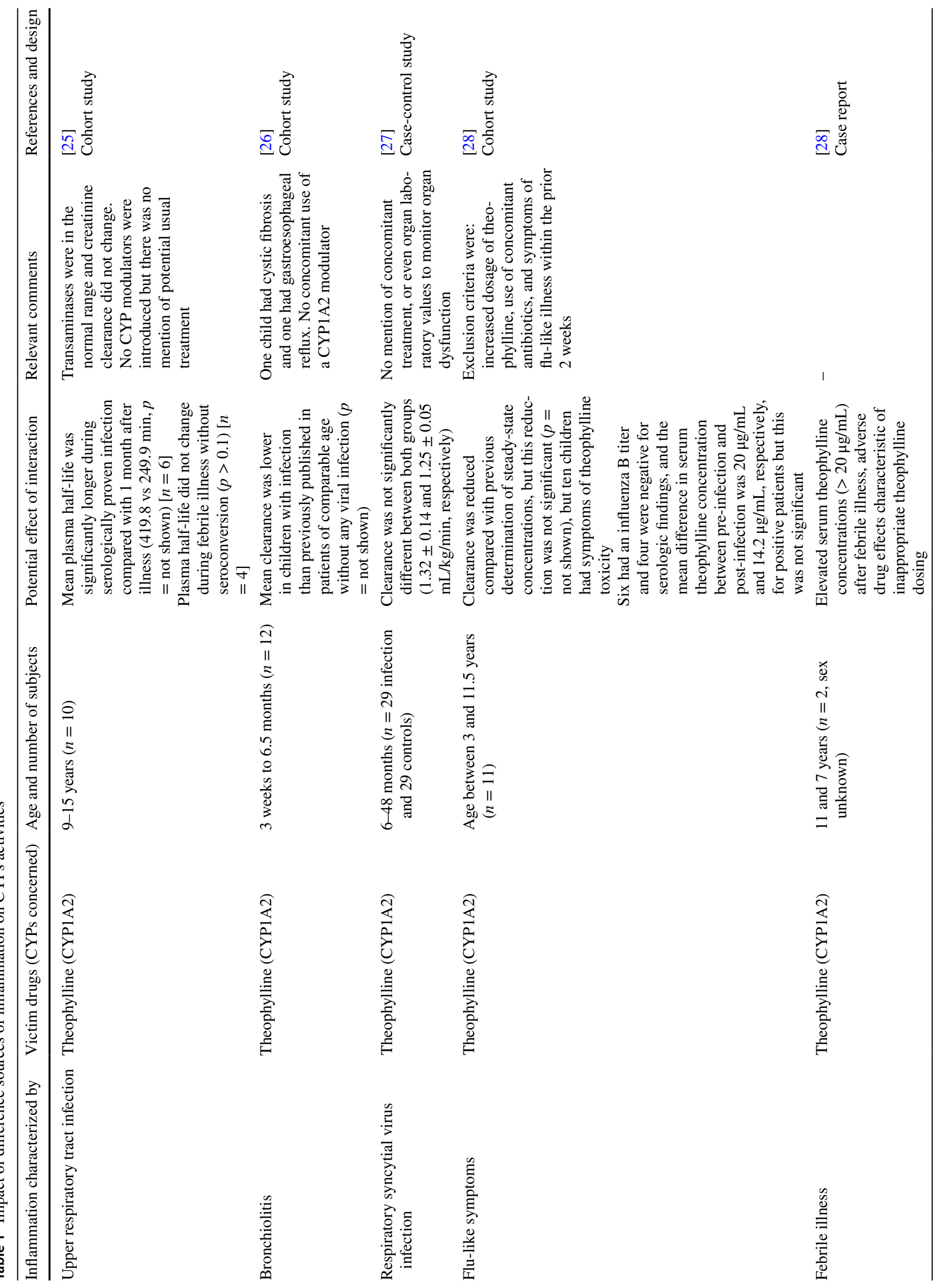




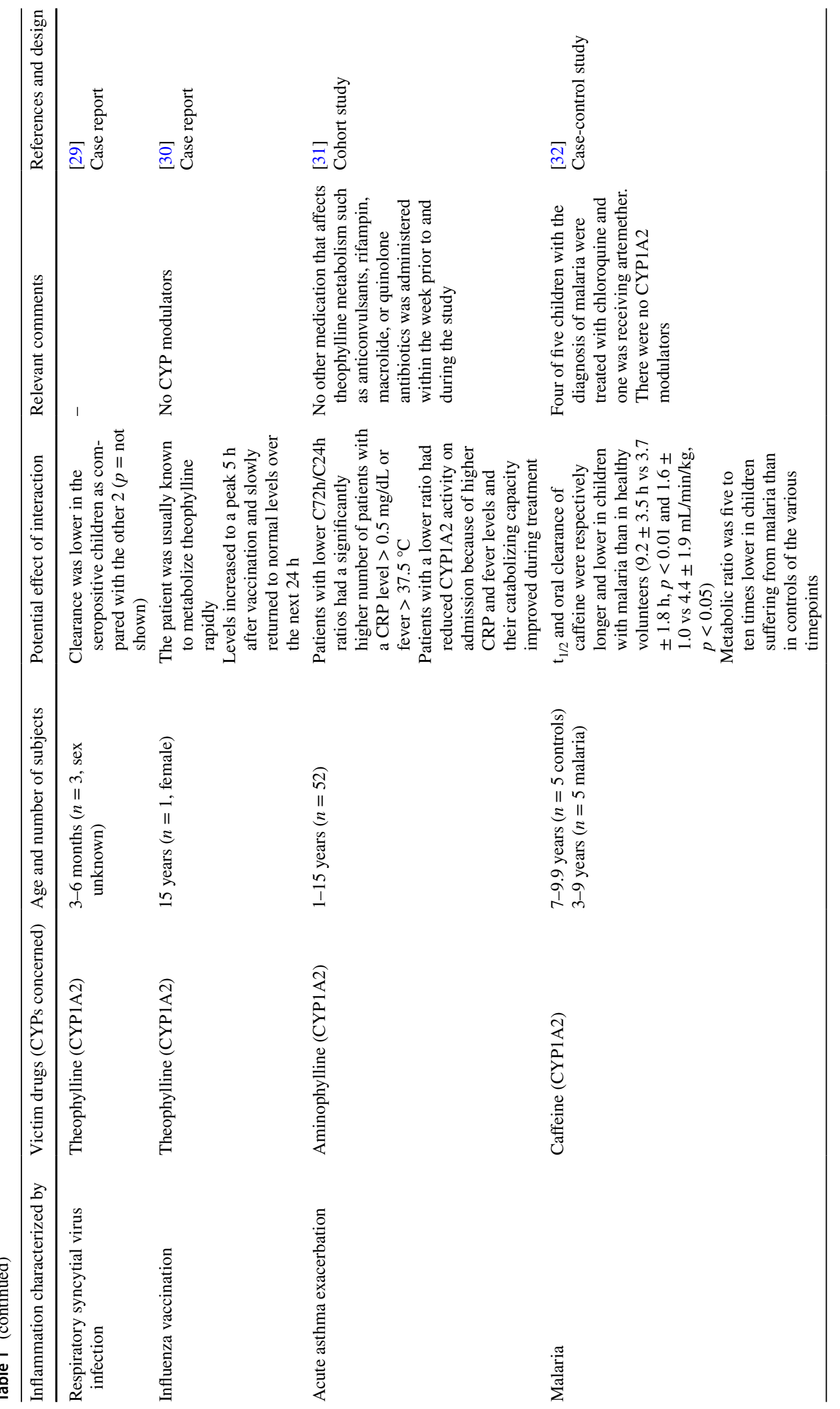

$\triangle$ Adis 


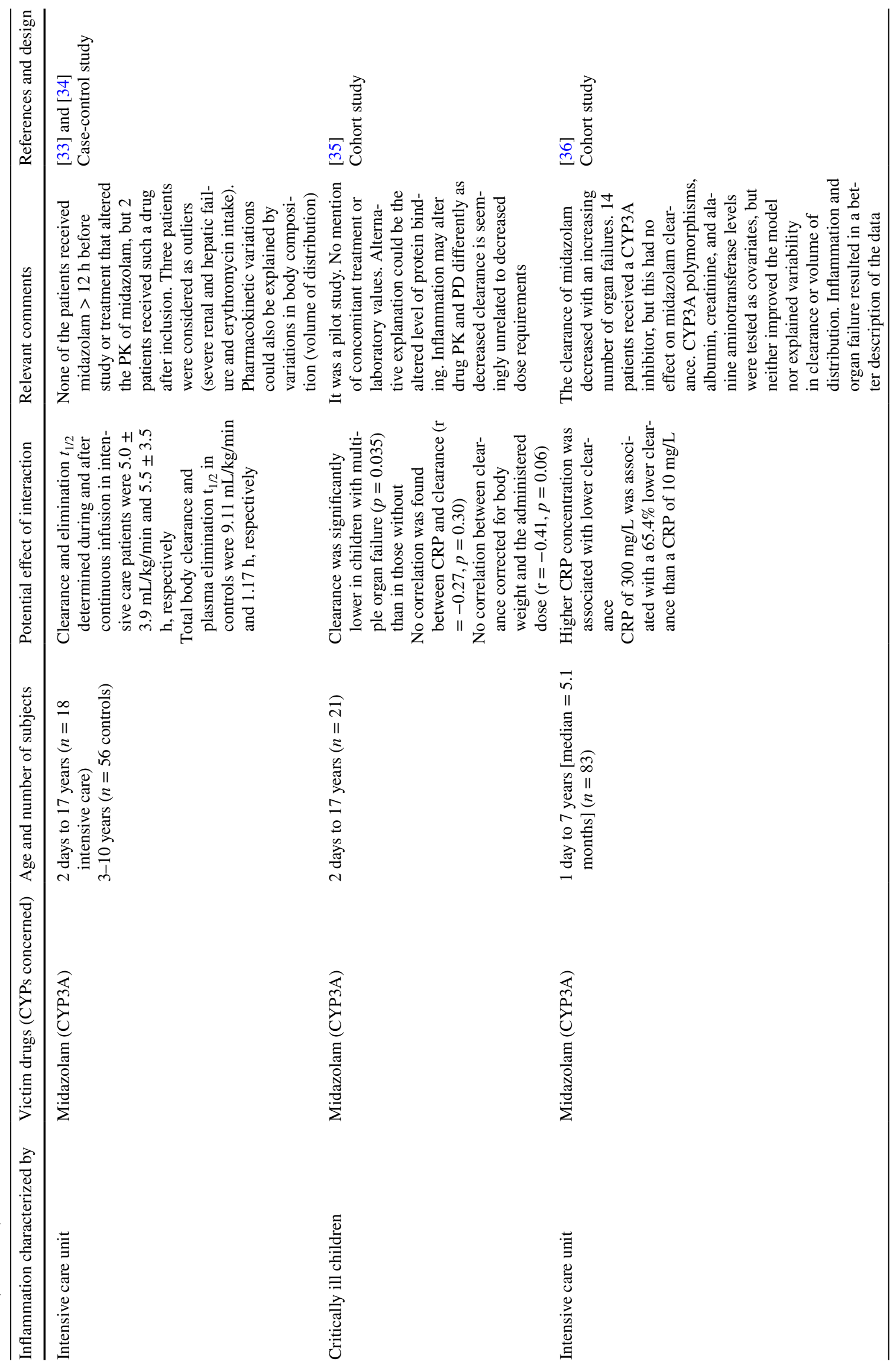




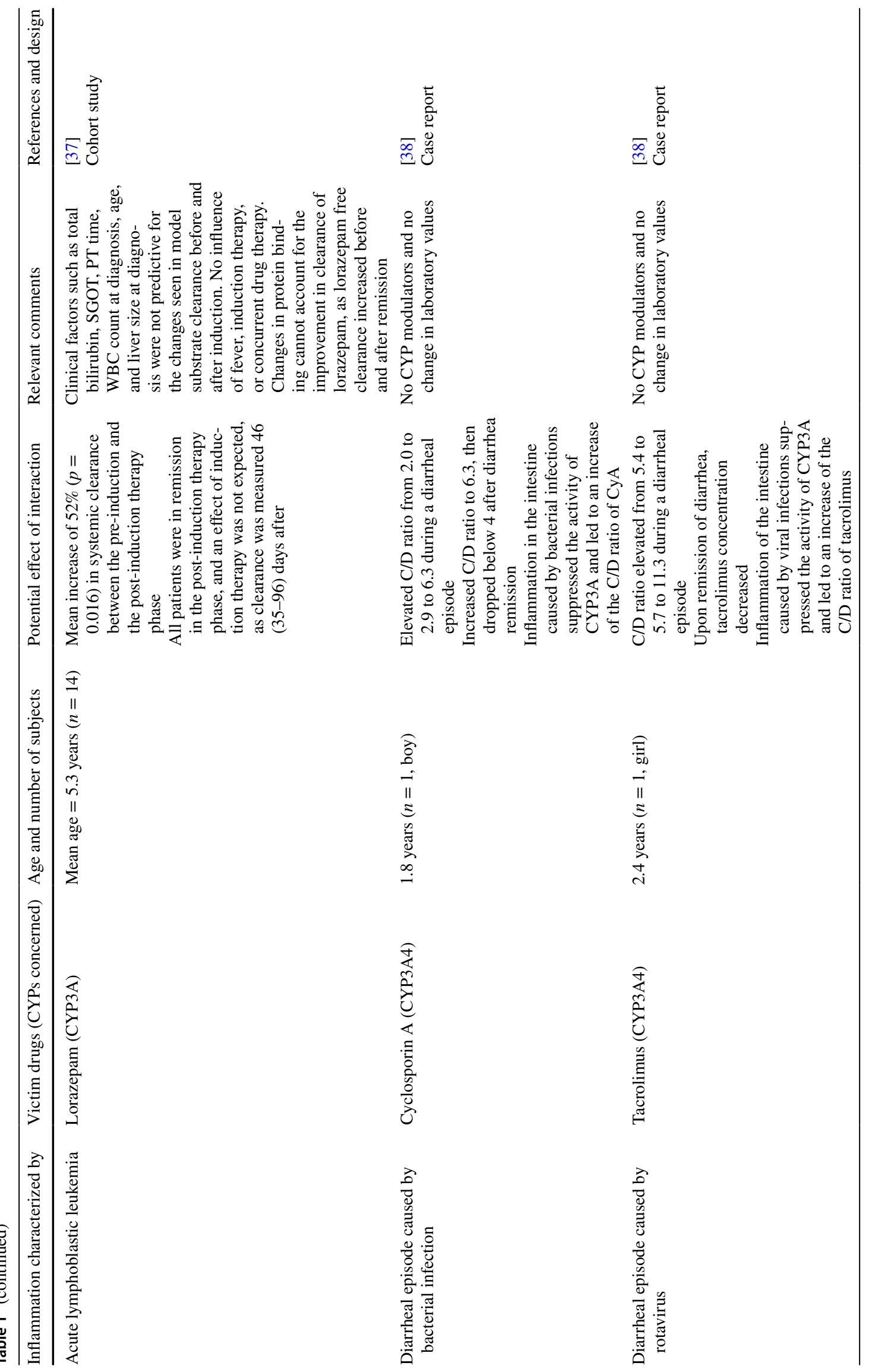


Impact of Inflammation on CYP450 in Pediatrics

1545

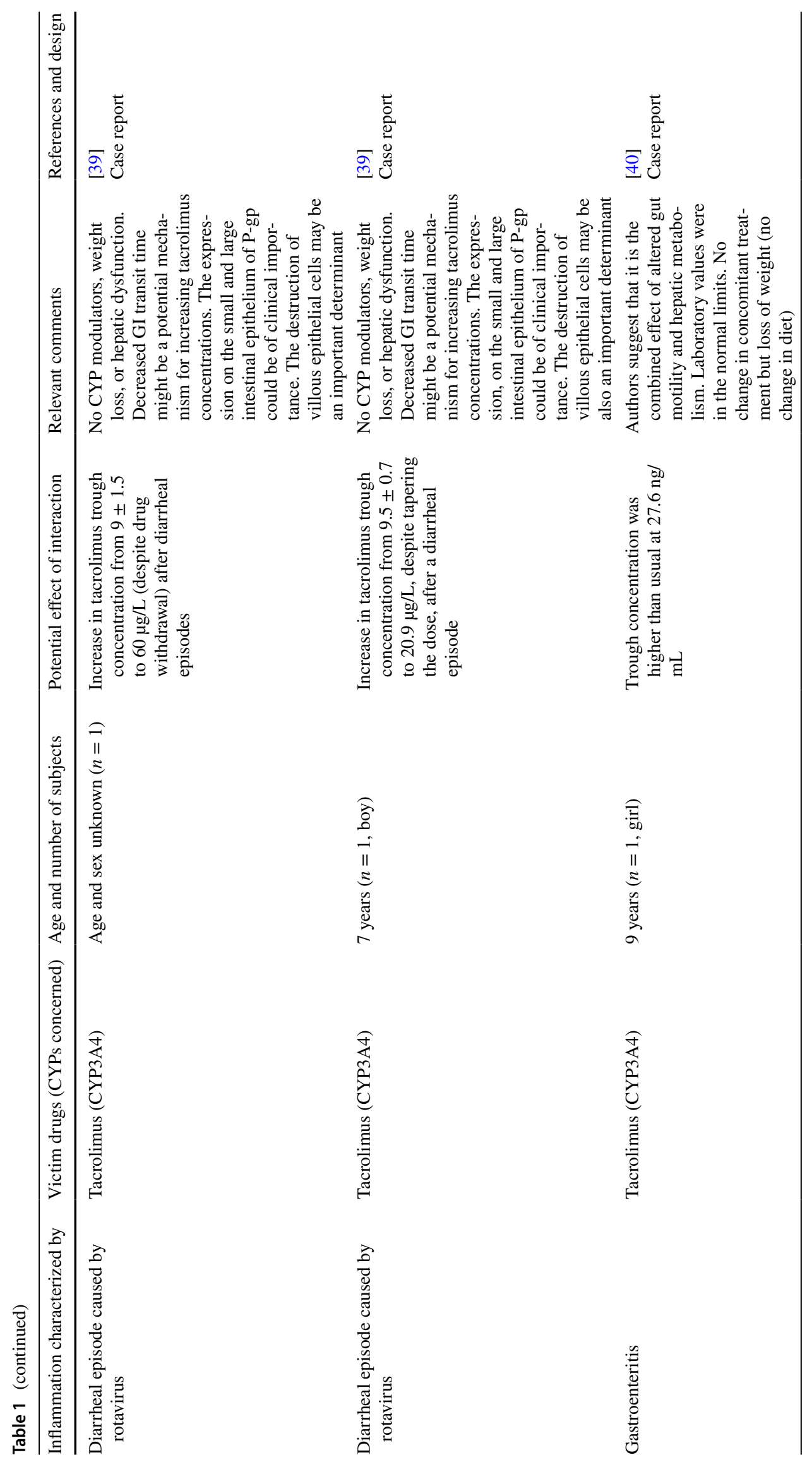

$\triangle$ Ads 


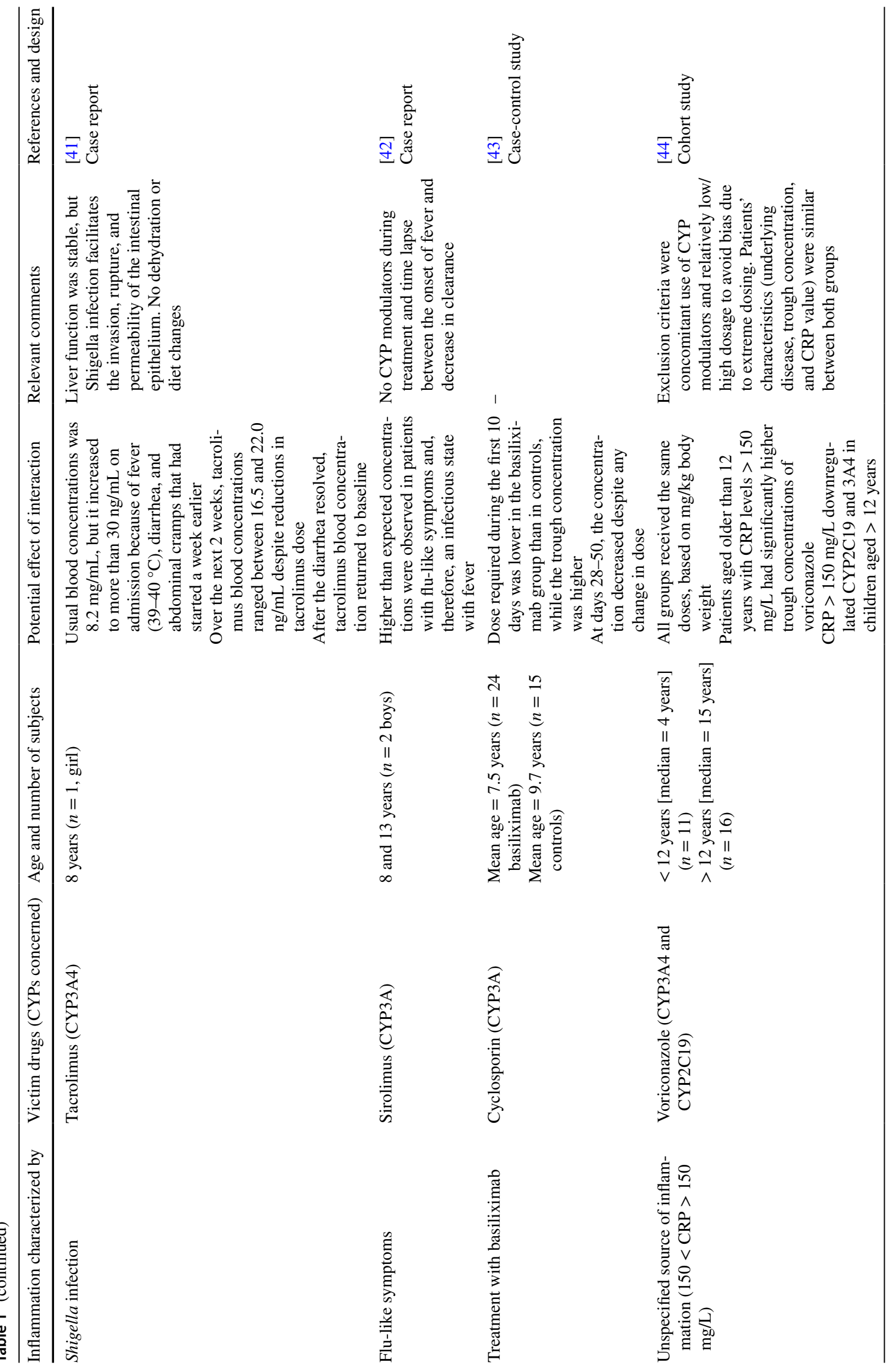




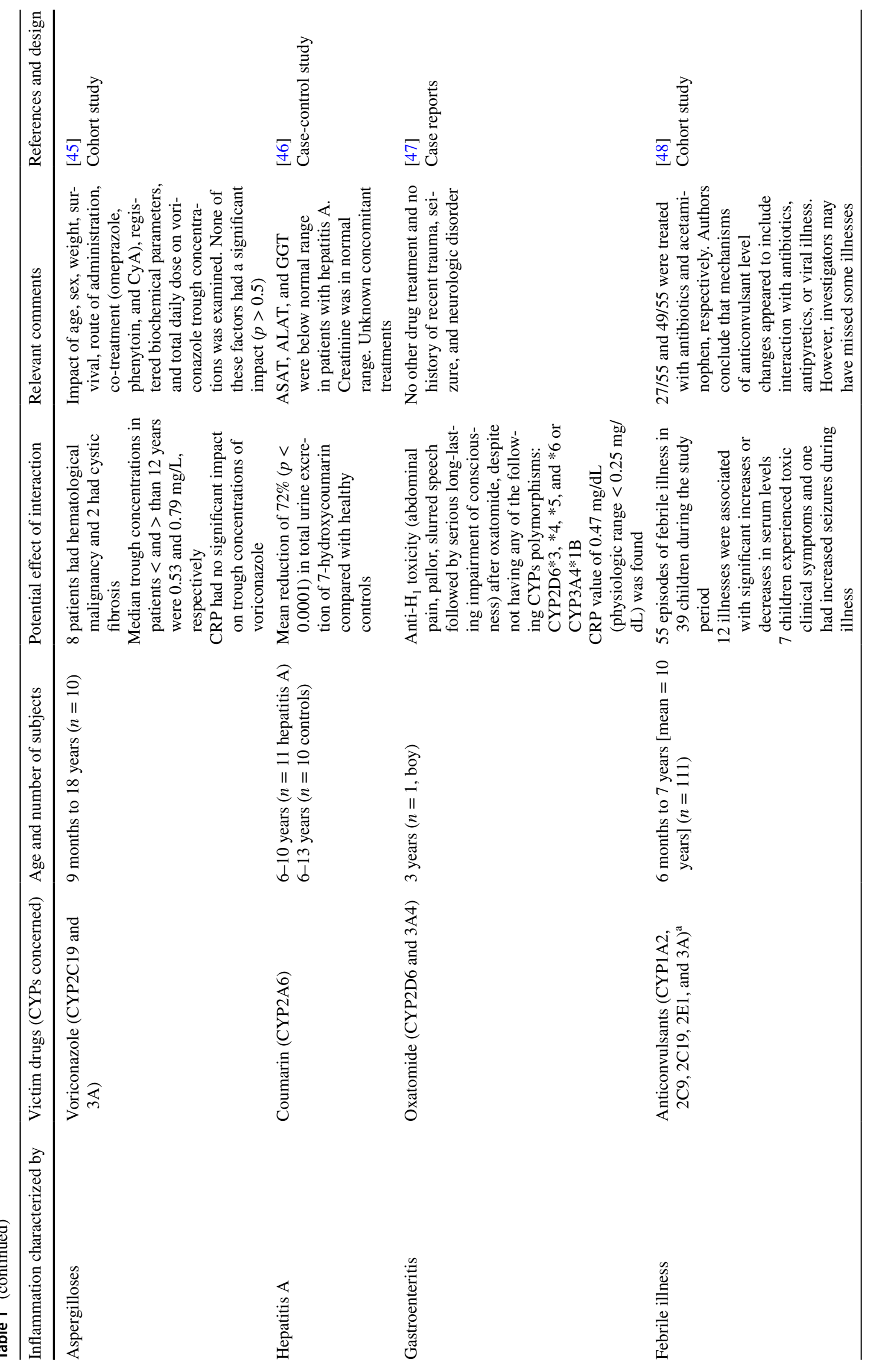




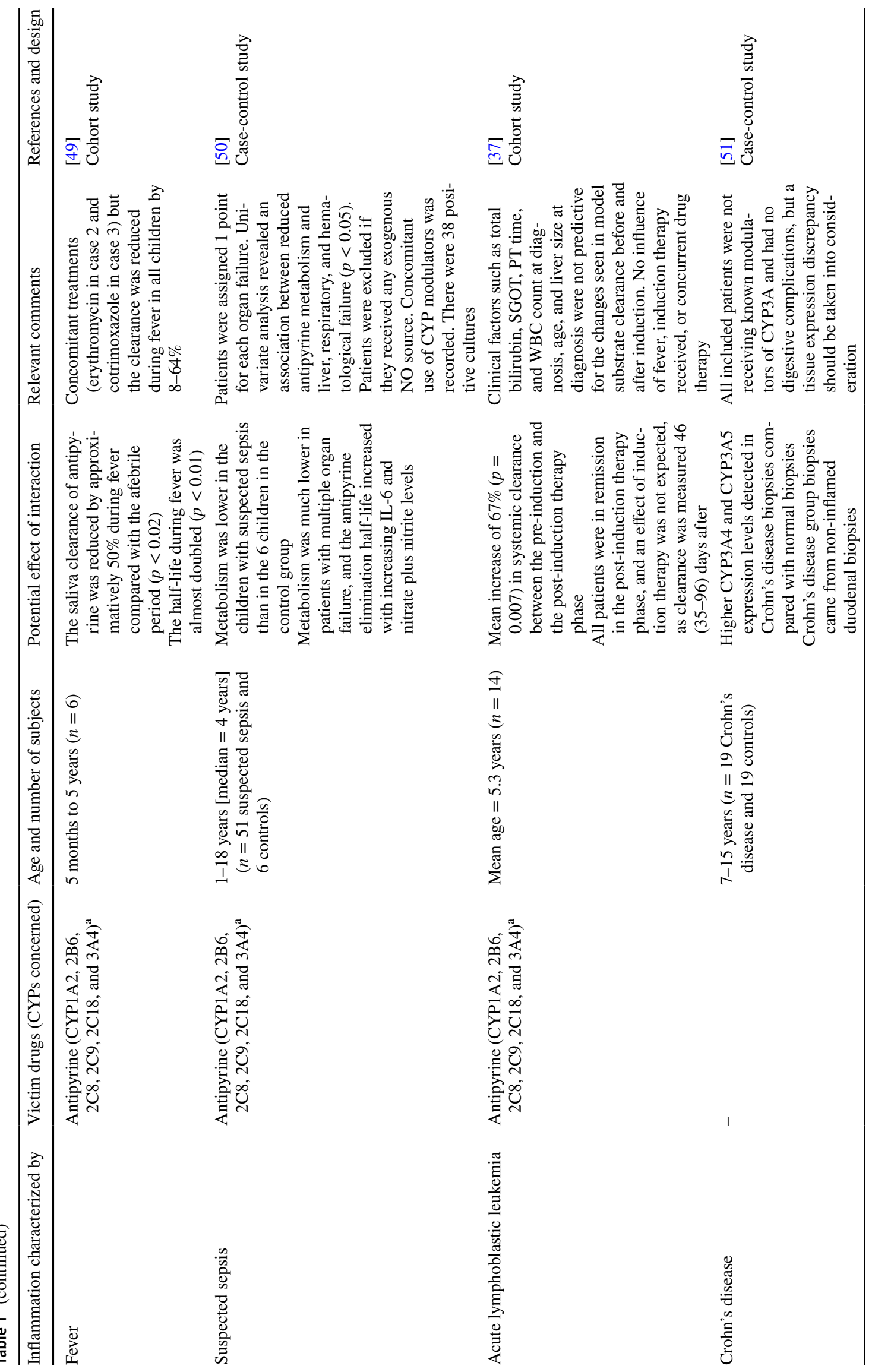




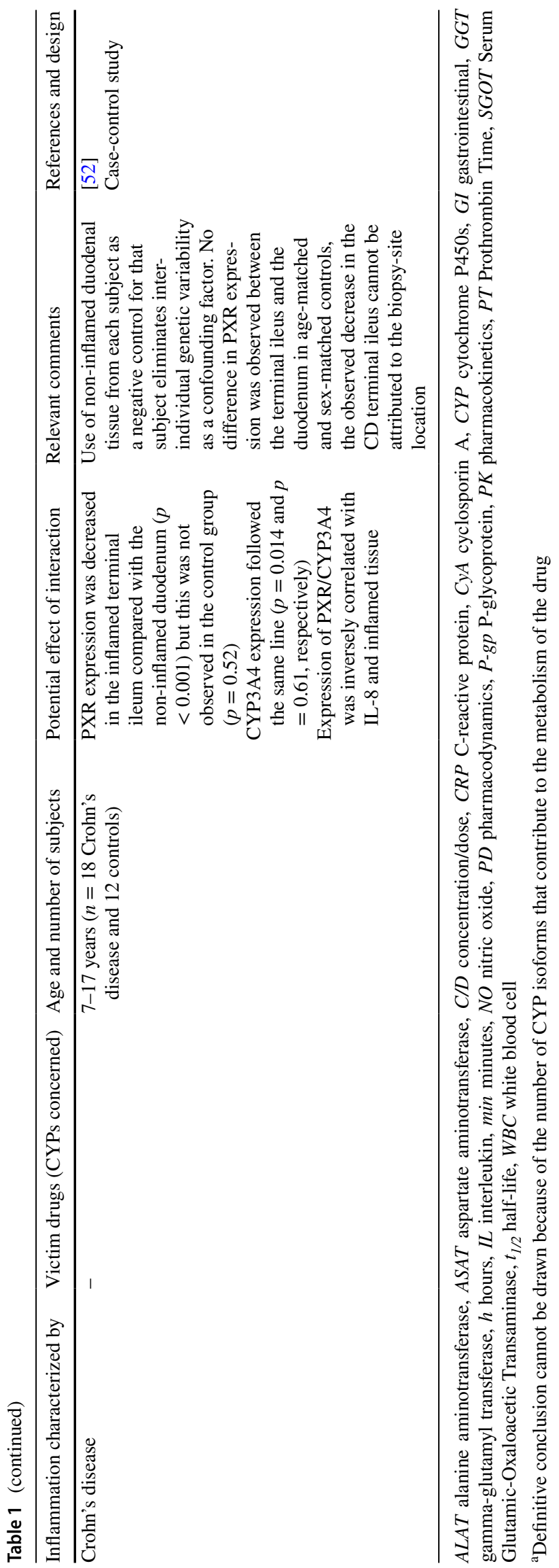

pharmacokinetic parameters. Indeed, the plasma concentrations of tacrolimus and CyA were higher, and doses lower, in patients with hepatitis $\mathrm{C}$ infection as compared with patients without hepatitis C infection [53-55]. Inversely, treatment of hepatitis $\mathrm{C}$ resulted in decreased tacrolimus and CyA concentrations and/or increased required doses [56-60]. Thus, the treatment of the infection allowed a return to baseline CYP3A activity, probably because the subsequent inflammation disappeared.

Basiliximab is another example where inflammation downregulated CYP3A activity similarly in children and adults. Indeed, concentrations of tacrolimus and $\mathrm{CyA}$ increased during the first days of basiliximab treatment both in adults and children [43, 61]. Moreover, concentrations decreased spontaneously after 30 days of basiliximab treatment, despite any dose modification [43, 61]. The authors suggested that the impact of basiliximab on drug metabolism was due to interleukin-2 [61]. The similar effects observed in adults and children could be explained by the intermediate developmental pattern of CYP3A4, as adult CYP3A activity is reached at the end of infancy and children were aged older than 2 years [17-19].

Regarding critically ill patients, CYP3A4 has been shown to be downregulated in adults and the decrease of CYP34 activity was correlated with the severity of organ failure [62, 63]. The same results were observed in pediatric intensive care unit patients. Metabolism of midazolam decreased with the severity of intensive care unit-induced inflammation as a consequence of CYP3A4 downregulation [33-36]. However, it is possible that mechanisms other than CYP regulation could also be responsible for the drug's pharmacokinetic alterations during inflammatory states, such as changes in plasma protein binding and renal excretion [64]. A study indeed showed that proinflammatory cytokines trigger an acute-phase response that could increase the unbound fraction of drugs [65]. In diabetic adults, the lack of differences in CyA daily doses, but the lower production of its metabolites, could be the consequences of variations in protein binding [66]. No other studies assessing CYPs other than CYP3A could be found in the literature. Those studies should be performed, as data in adults have shown that CYPs are regulated in an isoform-specific manner in critically ill patients [67].

In children with Crohn's disease, both CYP3A4 and CYP3A5 were upregulated, which is inconsistent with the previous observation of downregulation of CYP3A4 associated with higher C-reactive protein (CRP) levels, but could be explained by the fact that the biopsies were from noninflamed tissue [51]. In another study in children of the same age range, the expression of the nuclear hormone receptor PXR was decreased in inflamed tissues and, thus, CYP3A4 expression also decreased [52]. Further studies in children with inflammatory bowel disease should be initiated to 
understand these discrepancies, as well as in vitro studies to understand the underlying mechanisms. In adults, verapamil (CYP3A4, 1A2, 2C8, 2C9, and 2C18 substrate) and propranolol (CYP2D6 substrate) concentrations were significantly higher in patients with active Crohn's disease than in healthy volunteers or patients in remission $[68,69]$. The authors suggested that the reduced clearance could be attributed to CYP downregulation, but increased bioavailability due to downregulation of P-glycoprotein could not be ruled out [68]. However, a possible impact of the decrease in CYP content due to Crohn's disease should be kept in mind.

\subsection{CYP1A2}

In adults, the impact of inflammation on CYP1A2 activity has been well studied for two substrates (i.e., theophylline and clozapine) and a decrease in their clearances has been observed, as well as symptoms of clozapine toxicity [70-78]. In pediatrics, theophylline was the only studied substrate of CYP1A2, except one study with caffeine [32]. Theophylline has been a commonly used drug for asthma for over 50 years, but its narrow therapeutic index has made it disappear from current asthma guidelines [79, 80].

In line with what is found in adults, our literature review showed that infection may decrease CYP1A2 activity in children [25, 26, 28-30,32]. However, a study conducted in children aged 6-48 months $(n=58)$, showed that infection had no impact on theophylline clearance [27]. CYP1A2 has the slowest developmental pattern and a large heterogeneity in the impact of inflammation on its activity is expected, with increasing intensity as age advances [17-19]. Further investigations are needed to determine whether CYP1A2 is affected by inflammation in children.

\subsection{Other CYPs}

Antipyrine is an older drug metabolized by several CYPs (CYP1A2, 2B6, 2C8, 2C9, 2C18, and 3A4) and which has been widely used to investigate hepatic drug metabolism because it is almost completely absorbed from the intestine, has negligible plasma protein binding, a low hepatic extraction ratio, and is metabolized almost entirely by the liver [81]. In children, clearance of antipyrine appeared to be reduced during fever or suspected sepsis $[49,50]$. Moreover, the inhibition of metabolism was proportional to disease severity and interleukin-6 levels, and a return to baseline levels was observed with cancer resolution [37, 50]. Inflammation is present at all stages of cancer, with an apparent link between certain immune-mediated diseases or infection and cancer, such as inflammatory bowel disease or Helicobacter pylori that are associated with colorectal and gastric cancer, respectively [82]. CYP3A and CYP2C19 are two well-studied isoforms in cancer, and several studies have found impaired activity of these CYPs in adult patients with cancer [83-90]. Only one study has been conducted in children (mean age 5.3 years) with acute lymphoblastic leukemia, and CYPs also appear to be altered during the acute phase [37]. Further studies are needed in pediatric oncology and in different age groups because chemotherapeutic and antimicrobial agents for prophylaxis are CYP substrates. In adults, the downregulation of antipyrine metabolism was also observed during infection, diabetes, or interferon treatment [91-94].

Anticonvulsants studied in children during inflammation were carbamazepine (CYP1A2, CYP2C9, and CYP3A substrate), phenytoin (CYP2C9 and CYP2C19), valproate (CYP2C9), phenobarbital (CYP2C9 and CYP2C19), and ethosuximide (CYP2E1 and CYP3A) [48]. Only seven children out of 39 with a febrile illness experienced toxic clinical symptoms and one had increased seizures during the illness [48]. The authors conclude that nearly a quarter of patients with febrile illnesses experienced significant changes in drug concentrations, with 9\% developing clinical toxicity [48]. They suspected direct inhibition by antibiotics and plasma protein displacement by antibiotics and antipyretics, in addition to inhibition of CYP activity by viral infection [48]. In adults, the effect of inflammation was mostly studied with phenytoin with an increased risk of toxicity. For instance, a 52-year-old woman had toxic phenytoin concentrations with associated symptoms during the influenza illness and urinary excretion of the metabolite of mephenytoin among patients with liver disease or multiply injured was significantly lower than healthy controls $[67,95,96]$.

Voriconazole is mainly metabolized by CYP2C19 and CYP3A [97]. In adults, a cohort study found that the level of CRP was positively associated with the concentration/dose (C/D) ratio or through concentration of voriconazole and was negatively associated with the metabolic ratio expressed by [N-oxide voriconazole]/[voriconazole] [98-101]. Moreover, an elevated level of CRP was a risk factor for voriconazole overdose [102]. This could be explained by CYP2C19 and/or CYP3A downregulation due to inflammation, represented by elevated levels of CRP. In children, this association is less pronounced, as a significant association between CRP levels $>150 \mathrm{mg} / \mathrm{L}$ and higher voriconazole through concentrations was only observed in patients aged older than 12 years [44]. Moreover, another study conducted in children did not find an association between trough concentrations of voriconazole and CRP, but the cohort was very small and no distinction was made between older and younger children [45]. Possible explanations for this difference in association between CRP and CYP downregulation observed in children aged younger and older than 12 years are that the PK of voriconazole appears to be linear before 12 years of age and non-linear after [44]. The bioavailability of voriconazole indeed decreases (and clearance increases) in pediatric 
patients compared with adults, resulting in less saturation of PK processes and, thus, linear kinetics [12, 45]. This implies that first-pass metabolism is higher in the pediatric population and it was suggested that CYP-mediated clearance is higher in children under 12 years of age and thus that downregulation by inflammation had less impact on voriconazole metabolism [44]. However, CYP2C19 and CYP3A4 activity reaches that of an adult at the end of infancy and inflammation is expected to further inhibit CYP activity because there are more CYPs to downregulate [17-19]. One possible explanation is that enzymes other than CYPs are responsible for voriconazole clearance and that they are more expressed in children and less impacted by inflammation. Voriconazole is also metabolized by flavin-containing monooxygenase 3 , and the contribution of flavin-containing monooxygenase 3 and CYP2C19 has been shown to be five-fold and three-fold higher in children than in adults, respectively $[45,103]$. It is important to consider these non-CYP phase I drug-metabolizing enzymes because approximatively $25 \%$ of metabolically eliminated drugs are first subjected to nonCYP-mediated biotransformation [14]. Moreover, it seems that flavin-containing monooxygenase 3 and CYP2C19 have higher catalytic activity in children than in adults $[45,103]$. Another hypothesis is that the CYP2C19 contribution to CYP3A is more affected by inflammation. We have indeed previously demonstrated in adults that CYP3A was more impacted by inflammation than CYP2C19 [104].

\subsection{CYP Genotype}

The CYP genotype is an additional factor to be considered, as cytokines may not have the same impact on CYP activities depending on the basal genetic activity of CYPs. In adults, the different impact of inflammation on CYP2C19 and CYP2C9 depending on the genotypes has already been demonstrated $[105,106]$.

In children, the same conclusions can be drawn as oxotamide toxicity was observed in 3-year-old children who were not carriers of CYP2D6 or CYP3A4 main allelic variants at the time of the study, meaning that the reduced clearance is not caused by the manifestation of CYP2D $6 * 3, * 4$, $* 5$, and $* 6$ or CYP3A*1B [47]. It is therefore conceivable that the release of pro-inflammatory molecules such as CRP decreased CYP2D6 and/or CYP3A activities, eventually leading to an increase in the oxatomide plasmatic concentration [47].

\subsection{Limitations}

Our systematic review has some limitations, which suggest a cautious approach to these results. First, the manual search was performed in a single database and for published articles only, which cannot rule out publication bias and the potential for omissions. Furthermore, the studies found and selected were poorly comparable to each other, owing to the heterogeneity of their overall methodology. Finally, the observed PK and clinical impact are neither robust nor generalizable because of the diversity of the sources and severity of inflammation.

\section{Conclusions}

In recent years, numerous clinical studies and case reports evaluated in adults have reported a modification in CYP activities and pharmacokinetic parameters of drugs in the presence of inflammation. The latter being an important factor contributing to variation in CYP activities between and within individuals. This may have a clinical impact, as CYPs play an essential role in the bioactivation or elimination of many therapeutic agents. Current data suggest that inflammation has an isoform-specific and intensity-specific impact, i.e., CYP3A and CYP2C19 activities are downregulated and CYP2D6 activity does not change during inflammation, whereas the impact on CYP1A2, CYP2B6, and CYP2C9 remains unclear and needs further investigations. Some studies have even shown that CYP activity returns to baseline after the improvement of the disease. There is significant heterogeneity in inflammatory markers, depending on the disease involved and its degree of severity.

To our knowledge, no study has evaluated inflammationinduced CYP phenoconversion in children using a cocktail approach. In addition to the moral, ethical, and legal difficulties of conducting studies in children, a cocktail approach is further complicated by the multitude of probes administered. The development of endogenous markers of CYP metabolism could help overcome these obstacles and may have interesting opportunities to develop personalized medicine in the pediatric field. Indeed, in children, the proportion of the drug cleared by the metabolism of CYPs, the patient's genotype, and concomitant medications, but also ontogeny must also be taken into account. Inflammation has a different impact on CYP activity depending on age as the proportion of CYP changes depending on the isoform and extrapolation from adult data cannot be done automatically. Despite all this evidence, much remains to be done to know the impact of inflammation on CYPs activity in the pediatric population. Indeed, this review highlights that, beyond the fact that few studies have been conducted in pediatrics, almost no studies have been conducted in neonatal to early infancy, although this is the period when developmental changes are most important. Moreover, many diseases with underlying inflammation have not yet been studied and the few existing studies do not focus on CYPs other than CYP3A and CYP1A2. 


\section{Declarations}

Funding Open Access funding provided by Université de Genève.

Conflict of Interest/Competing Interests The authors declare that the research was conducted in the absence of any commercial or financial relationships that could be construed as a potential conflict of interest.

Ethics Approval Not applicable.

Consent to Participate Not applicable.

Consent for Publication Not applicable.

Availability of Data and Material The data that support the findings of this study are available from all contributing authors and upon reasonable request.

\section{Code Availability Not applicable.}

Authors' Contributions CL participated in the manuscript conceptualization, experimental design, writing, data analysis, and overall manuscript review. FR, CFS, and VR participated in the manuscript conceptualization, experimental design, data analysis, supervision, and overall manuscript review. JAD participated in the supervision and overall manuscript review.

Open Access This article is licensed under a Creative Commons Attribution-NonCommercial 4.0 International License, which permits any non-commercial use, sharing, adaptation, distribution and reproduction in any medium or format, as long as you give appropriate credit to the original author(s) and the source, provide a link to the Creative Commons licence, and indicate if changes were made. The images or other third party material in this article are included in the article's Creative Commons licence, unless indicated otherwise in a credit line to the material. If material is not included in the article's Creative Commons licence and your intended use is not permitted by statutory regulation or exceeds the permitted use, you will need to obtain permission directly from the copyright holder. To view a copy of this licence, visit http://creativecommons.org/licenses/by-nc/4.0/.

\section{References}

1. Gabay C, Kushner I. Acute-phase proteins and other systemic responses to inflammation. N Engl J Med. 1999;340:448-54.

2. Renton KW. Alteration of drug biotransformation and elimination during infection and inflammation. Pharmacol Ther. 2001;92:147-63.

3. Morgan ET, Goralski KB, Piquette-Miller M, Renton KW, Robertson GR, Chaluvadi MR, et al. Regulation of drug-metabolizing enzymes and transporters in infection, inflammation, and cancer. Drug Metab Dispos. 2008;36:205-16.

4. Aitken AE, Richardson TA, Morgan ET. Regulation of drugmetabolizing enzymes and transporters in inflammation. Annu Rev Pharmacol Toxicol. 2006;46:123-49.

5. Morgan ET. Impact of infectious and inflammatory disease on cytochrome P450-mediated drug metabolism and pharmacokinetics. Clin Pharmacol Ther. 2009;85:434-8.

6. de Jong LM, Jiskoot W, Swen JJ, Manson ML. Distinct effects of inflammation on cytochrome $\mathrm{P} 450$ regulation and drug metabolism: lessons from experimental models and a potential role for pharmacogenetics. Genes (Basel). 2020;11:1509.
7. Wienkers LC, Heath TG. Predicting in vivo drug interactions from in vitro drug discovery data. Nat Rev Drug Discov. 2005;4:825-33.

8. Manceau H, Amrani K, Peoc'h K. Personalized medicine, pharmacogenomic and companion biomarker. Ann Biol Clin (Paris). 2017;75:631-6.

9. Stavropoulou E, Pircalabioru GG, Bezirtzoglou E. The role of cytochromes P450 in infection. Front Immunol. 2018;9:89.

10. Germolec DR, Shipkowski KA, Frawley RP, Evans E. Markers of inflammation. Methods Mol Biol. 1803;2018:57-79.

11. Vet NJ, de Hoog M, Tibboel D, de Wildt SN. The effect of inflammation on drug metabolism: a focus on pediatrics. Drug Discov Today. 2011;16:435-42.

12. Lim SY, Pettit RS. Pharmacokinetic considerations in pediatric pharmacotherapy. Am J Health Syst Pharm. 2019;76:1472-80.

13. Alcorn J, McNamara PJ. Ontogeny of hepatic and renal systemic clearance pathways in infants: part I. Clin Pharmacokinet. 2002;41:959-98.

14. Chapron B, Chapron A, Leeder JS. Recent advances in the ontogeny of drug disposition. Br J Clin Pharmacol. 2021. https://doi. org/10.1111/bcp.14821.

15. Kearns GL, Abdel-Rahman SM, Alander SW, Blowey DL, Leeder JS, Kauffman RE. Developmental pharmacology: drug disposition, action, and therapy in infants and children. N Engl J Med. 2003;349:1157-67.

16. Magliocco G, Rodieux F, Desmeules J, Samer CF, Daali Y. Toward precision medicine in pediatric population using cytochrome $\mathrm{P} 450$ phenotyping approaches and physiologically based pharmacokinetic modeling. Pediatr Res. 2020;87:441-9.

17. van den Anker J, Reed MD, Allegaert K, Kearns GL. Developmental changes in pharmacokinetics and pharmacodynamics. $\mathbf{J}$ Clin Pharmacol. 2018;58(Suppl. 10):S10-25.

18. Hines RN, McCarver DG. The ontogeny of human drug-metabolizing enzymes: phase I oxidative enzymes. J Pharmacol Exp Ther. 2002;300:355-60.

19. Kodidela S, Kumar SS, Uppugunduri CR. Developmental pattern of hepatic drug-metabolizing enzymes in pediatric population and its role in optimal drug treatment. Arch Med Health Sci. 2017;5(1):115-22.

20. Hines RN. The ontogeny of drug metabolism enzymes and implications for adverse drug events. Pharmacol Ther. 2008;118:250-67.

21. Upreti VV, Wahlstrom JL. Meta-analysis of hepatic cytochrome $\mathrm{P} 450$ ontogeny to underwrite the prediction of pediatric pharmacokinetics using physiologically based pharmacokinetic modeling. J Clin Pharmacol. 2016;56:266-83.

22. Moher D, Liberati A, Tetzlaff J, Altman DG, PRISMA Group. Preferred reporting items for systematic reviews and meta-analyses: the PRISMA statement. BMJ. 2009;339:b2535.

23. UpToDate. Smarter decisions: better care. https://www.uptodate. com/home. Accessed 21 Apr 2020

24. Samer CF, Lorenzini KI, Rollason V, Daali Y, Desmeules JA. Applications of CYP450 testing in the clinical setting. Mol Diagn Ther. 2013;17:165-84.

25. Chang KC, Bell TD, Lauer BA, Chai H. Altered theophylline pharmacokinetics during acute respiratory viral illness. Lancet. 1978;1:1132-3.

26. Franko TG, Powell DA, Nahata MC. Pharmacokinetics of theophylline in infants with bronchiolitis. Eur J Clin Pharmacol. 1982;23:123-7.

27. Muslow HA, Bernard L, Brown RD, Jamison RM, Manno JE, Bocchini JA, et al. Lack of effect of respiratory syncytial virus infection on theophylline disposition in children. J Pediatr. 1992;121:466-71. 
28. Kraemer MJ, Furukawa CT, Koup JR, Shapiro GG, Pierson WE, Bierman CW. Altered theophylline clearance during an influenza B outbreak. Pediatrics. 1982;69:476-80.

29. Koren G, Greenwald M. Decreased theophylline clearance causing toxicity in children during viral epidemics. J Asthma. 1985;22:75-9.

30. Walker S, Schreiber L, Middelkamp JN. Serum theophylline levels after influenza vaccination. Can Med Assoc J. 1981;125:243-4

31. Yamaguchi A, Tateishi T, Okano Y, Matuda T, Akimoto Y, Miyoshi T, et al. Higher incidence of elevated body temperature or increased C-reactive protein level in asthmatic children showing transient reduction of theophylline metabolism. J Clin Pharmacol. 2000;40:284-9.

32. Akinyinka OO, Sowunmi A, Honeywell R, Renwick AG. The pharmacokinetics of caffeine in Nigerian children suffering from malaria and kwashiorkor. Eur J Clin Pharmacol. 2000;56:153-8.

33. de Wildt SN, de Hoog M, Vinks AA, van der Giesen E, van den Anker JN. Population pharmacokinetics and metabolism of midazolam in pediatric intensive care patients. Crit Care Med. 2003;31:1952-8.

34. Payne K, Mattheyse FJ, Liebenberg D, Dawes T. The pharmacokinetics of midazolam in paediatric patients. Eur J Clin Pharmacol. 1989;37:267-72.

35. Vet NJ, de Hoog M, Tibboel D, de Wildt SN. The effect of critical illness and inflammation on midazolam therapy in children. Pediatr Crit Care Med. 2012;13:e48-50.

36. Vet NJ, Brussee JM, de Hoog M, Mooij MG, Verlaat CWM, Jerchel IS, et al. Inflammation and organ failure severely affect midazolam clearance in critically ill children. Am J Respir Crit Care Med. 2016;194:58-66.

37. Relling MV, Crom WR, Pieper JA, Cupit GC, Rivera GK, Evans WE. Hepatic drug clearance in children with leukemia: changes in clearance of model substrates during remission-induction therapy. Clin Pharmacol Ther. 1987;41:651-60.

38. Maezono S, Sugimoto K, Sakamoto K, Ohmori M, Hishikawa S, Mizuta K, et al. Elevated blood concentrations of calcineurin inhibitors during diarrheal episode in pediatric liver transplant recipients: involvement of the suppression of intestinal cytochrome P450 3A and P-glycoprotein. Pediatr Transplant. 2005;9:315-23

39. Frühwirth M, Fischer H, Simma B, Hochleitner B, Königsrainer A, Margreiter R, et al. Rotavirus infection as cause of tacrolimus elevation in solid-organ-transplanted children. Pediatr Transplant. 2001;5:88-92.

40. Eades SK, Boineau FG, Christensen ML. Increased tacrolimus levels in a pediatric renal transplant patient attributed to chronic diarrhea. Pediatr Transplant. 2000;4:63-6.

41. Zylber-Katz E, Granot E. Abrupt increase of tacrolimus blood levels during an episode of Shigella infection in a child after liver transplantation. Ther Drug Monit. 2001;23:647-9.

42. Mizuno T, O'Brien MM, Vinks AA. Significant effect of infection and food intake on sirolimus pharmacokinetics and exposure in pediatric patients with acute lymphoblastic leukemia. Eur J Pharm Sci. 2019;128:209-14

43. Strehlau J, Pape L, Offner G, Nashan B, Ehrich JH. Interleukin-2 receptor antibody-induced alterations of ciclosporin dose requirements in paediatric transplant recipients. Lancet. 2000;356:1327-8.

44. Ter Avest M, Veringa A, van den Heuvel ER, Kosterink JGW, Schölvinck EH, Tissing WJE, et al. The effect of inflammation on voriconazole trough concentrations in children. Br J Clin Pharmacol. 2017;83:678-80.

45. Spriet I, Cosaert K, Renard M, Uyttebroeck A, Meyts I, Proesmans $\mathrm{M}$, et al. Voriconazole plasma levels in children are highly variable. Eur J Clin Microbiol Infect Dis. 2011;30:283-7.
46. Pasanen M, Rannala Z, Tooming A, Sotaniemi EA, Pelkonen $\mathrm{O}$, Rautio A. Hepatitis A impairs the function of human hepatic CYP2A6 in vivo. Toxicology. 1997;123:177-84.

47. Antoniazzi S, Cattaneo D, Perrone V, Carnovale C, Cherubini $\mathrm{S}$, Mugolino MC, et al. Inflammation and neurological adverse drugs reactions: a case of long lasting impaired consciousness after oxatomide administration in a patient with gastroenteritis. Ital J Pediatr. 2012;38:11.

48. Goulden KJ, Camfield PR, Camfield CS, Tibbles JA, Dooley JM, Fraser AD, et al. Changes in serum anticonvulsant levels with febrile illness in children with epilepsy. Can J Neurol Sci. 1988;15:281-5.

49. Forsyth JS, Moreland TA, Rylance GW. The effect of fever on antipyrine metabolism in children. Br J Clin Pharmacol. 1982;13:811-5.

50. Carcillo JA, Doughty L, Kofos D, Frye RF, Kaplan SS, Sasser $\mathrm{H}$, et al. Cytochrome $\mathrm{P} 450$ mediated-drug metabolism is reduced in children with sepsis-induced multiple organ failure. Intensive Care Med. 2003;29:980-4.

51. Fakhoury M, Lecordier J, Medard Y, Peuchmaur M, Jacqz-Agrain E. Impact of inflammation on the duodenal mRNA expression of CYP3A and P-glycoprotein in children with Crohn's disease. Inflamm Bowel Dis. 2006;12:745-9.

52. Shakhnovich V, Vyhlidal C, Friesen C, Hildreth A, Singh V, Daniel J, et al. Decreased pregnane $\mathrm{X}$ receptor expression in children with active Crohn's disease. Drug Metab Dispos. 2016;44:1066-9.

53. Latorre A, Morales E, Gonzalez E, Herrero JC, Ortiz M, Sierra $\mathrm{P}$, et al. Clinical management of renal transplant patients with hepatitis $\mathrm{C}$ virus infection treated with cyclosporine or tacrolimus. Transplant Proc. 2002;34:63-4.

54. Tuncer M, Süleymanlar G, Ersoy FF, Yakupoğlu G. Effects of hepatitis $\mathrm{C}$ virus infection on cyclosporine trough levels in renal transplant patients. Transplant Proc. 2000;32:569-71.

55. Wolffenbüttel L, Poli DD, Manfro RC, Gonçalves LFS. Cyclosporine pharmacokinetics in anti-HCV+ patients. Clin Transplant. 2004;18:654-60.

56. Smolders EJ, Pape S, de Kanter CTMM, van den Berg AP, Drenth JPH, Burger DM. Decreased tacrolimus plasma concentrations during HCV therapy: a drug-drug interaction or is there an alternative explanation? Int J Antimicrob Agents. 2017;49:379-82.

57. Kawaoka T, Imamura M, Morio K, Nakamura Y, Tsuge M, Nelson Hayes C, et al. Three patients treated with daclatasvir and asunaprevir for recurrent hepatitis $\mathrm{C}$ after liver transplantation: case report. Hepatol Res. 2016;46:707-12.

58. Raschzok N, Schott E, Reutzel-Selke A, Damrah I, Gül-Klein S, Strücker B, et al. The impact of directly acting antivirals on the enzymatic liver function of liver transplant recipients with recurrent hepatitis C. Transpl Infect Dis. 2016;18:896-903.

59. Ueda Y, Uemoto S. Decreased tacrolimus concentration following a temporal increase during interferon-free therapy with asunaprevir and daclatasvir in patients with recurrent hepatitis C after liver transplantation. Transpl Int. 2016;29:119-21.

60. Kugelmas M, Osgood MJ, Trotter JF, Bak T, Wachs M, Forman L, et al. Hepatitis C virus therapy, hepatocyte drug metabolism, and risk for acute cellular rejection. Liver Transpl. 2003;9:1159-65.

61. Sifontis NM, Benedetti E, Vasquez EM. Clinically significant drug interaction between basiliximab and tacrolimus in renal transplant recipients. Transplant Proc. 2002;34:1730-2.

62. Kruger PS, Freir NM, Venkatesh B, Robertson TA, Roberts MS, Jones M. A preliminary study of atorvastatin plasma concentrations in critically ill patients with sepsis. Intensive Care Med. 2009;35:717-21 
63. Shelly MP, Mendel L, Park GR. Failure of critically ill patients to metabolise midazolam. Anaesthesia. 1987;42:619-26.

64. Hefner G, Falter T, Bruns K, Hiemke C. Elevated risperidone serum concentrations during acute inflammation, two cases. Int J Psychiatry Med. 2015;50:335-44.

65. Gorski JC, Hall SD, Becker P, Affrime MB, Cutler DL, HaehnerDaniels B. In vivo effects of interleukin-10 on human cytochrome P450 activity. Clin Pharmacol Ther. 2000;67:32-43.

66. Akhlaghi F, Dostalek M, Falck P, Mendonza AE, Amundsen R, Gohh RY, et al. The concentration of cyclosporine metabolites is significantly lower in kidney transplant recipients with diabetes mellitus. Ther Drug Monit. 2012;34:38-45.

67. Harbrecht BG, Frye RF, Zenati MS, Branch RA, Peitzman AB. Cytochrome P-450 activity is differentially altered in severely injured patients. Crit Care Med. 2005;33:541-6.

68. Sanaee F, Clements JD, Waugh AWG, Fedorak RN, Lewanczuk R, Jamali F. Drug-disease interaction: Crohn's disease elevates verapamil plasma concentrations but reduces response to the drug proportional to disease activity. Br J Clin Pharmacol. 2011;72:787-97.

69. Schneider RE, Babb J, Bishop H, Mitchard M, Hoare AM. Plasma levels of propranolol in treated patients with coeliac disease and patients with Crohn's disease. Br Med J. 1976;2:794-5.

70. Khan Z, Khan MS. Rare case of theophylline toxicity due to influenza A infection in an adult with asthma. Am J Ther. 2019;26:e553-5.

71. Vozeh S, Powell JR, Riegelman S, Costello JF, Sheiner LB, Hopewell PC. Changes in theophylline clearance during acute illness. JAMA. 1978;240:1882-4.

72. Leung JG, Nelson S, Takala CR, Gören JL. Infection and inflammation leading to clozapine toxicity and intensive care: a case series. Ann Pharmacother. 2014;48:801-5.

73. Haack MJ, Bak MLFJ, Beurskens R, Maes M, Stolk LML, Delespaul PAEG. Toxic rise of clozapine plasma concentrations in relation to inflammation. Eur Neuropsychopharmacol. 2003; 13:381-5.

74. Clark SR, Warren NS, Kim G, Jankowiak D, Schubert KO, Kisely $\mathrm{S}$, et al. Elevated clozapine levels associated with infection: a systematic review. Schizophr Res. 2018;192:50-6.

75. de Leon J, Diaz FJ. Serious respiratory infections can increase clozapine levels and contribute to side effects: a case report. Prog Neuropsychopharmacol Biol Psychiatry. 2003;27:1059-63.

76. Jecel J, Michel TM, Gutknecht L, Schmidt D, Pfuhlmann B, Jabs BE. Toxic clozapine serum levels during acute urinary tract infection: a case report. Eur J Clin Pharmacol. 2005;60:909-10.

77. Toft P, Heslet L, Hansen M, Klitgaard NA. Theophylline and ethylenediamine pharmacokinetics following administration of aminophylline to septic patients with multiorgan failure. Intensive Care Med. 1991;17:465-8.

78. Williams SJ, Baird-Lambert JA, Farrell GC. Inhibition of theophylline metabolism by interferon. Lancet. 1987;2:939-41.

79. Weinberger M, Hendeles L. Theophylline in asthma. N Engl J Med. 1996;334:1380-8.

80. Al-Moamary MS, Alhaider SA, Alangari AA, Idrees MM, Zeitouni MO, Ghobain MOA, et al. The Saudi Initiative for Asthma-2021 update: guidelines for the diagnosis and management of asthma in adults and children. Ann Thorac Med. 2021;16:4-56.

81. Robertz-Vaupel GM, Lindecken KD, Edeki T, Funke C, Belwon S, Dengler HJ. Disposition of antipyrine in patients with extensive metastatic liver disease. Eur J Clin Pharmacol. 1992;42:465-9.

82. Harvey RD, Morgan ET. Cancer, inflammation, and therapy: effects on cytochrome p450-mediated drug metabolism and implications for novel immunotherapeutic agents. Clin Pharmacol Ther. 2014;96:449-57.
83. Chen YL, Le Vraux V, Leneveu A, Dreyfus F, Stheneur A, Florentin I, et al. Acute-phase response, interleukin-6, and alteration of cyclosporine pharmacokinetics. Clin Pharmacol Ther. 1994;55:649-60.

84. Rivory LP, Slaviero KA, Clarke SJ. Hepatic cytochrome P450 $3 \mathrm{~A}$ drug metabolism is reduced in cancer patients who have an acute-phase response. Br J Cancer. 2002;87:277-80.

85. Alexandre J, Rey E, Girre V, Grabar S, Tran A, Montheil V, et al. Relationship between cytochrome 3A activity, inflammatory status and the risk of docetaxel-induced febrile neutropenia: a prospective study. Ann Oncol. 2007;18:168-72.

86. Charles KA, Rivory LP, Stockler MR, Beale P, Beith J, Boyer $\mathrm{M}$, et al. Predicting the toxicity of weekly docetaxel in advanced cancer. Clin Pharmacokinet. 2006;45:611-22.

87. Williams ML, Bhargava P, Cherrouk I, Marshall JL, Flockhart DA, Wainer IW. A discordance of the cytochrome P450 2C19 genotype and phenotype in patients with advanced cancer. Br J Clin Pharmacol. 2000;49:485-8.

88. Burns KE, Goldthorpe MA, Porteus F, Browett P, Helsby NA. CYP2C19 genotype-phenotype discordance in patients with multiple myeloma leads to an acquired loss of drug-metabolising activity. Cancer Chemother Pharmacol. 2014;73:651-5.

89. Helsby NA, Lo W-Y, Sharples K, Riley G, Murray M, Spells $\mathrm{K}$, et al. CYP2C19 pharmacogenetics in advanced cancer: compromised function independent of genotype. Br J Cancer. 2008;99:1251-5.

90. Yasu T, Konuma T, Kato S, Kurokawa Y, Takahashi S, Tojo A. Serum C-reactive protein levels affect the plasma voriconazole trough levels in allogeneic hematopoietic cell transplant recipients. Leuk Lymphoma. 2017;58:2731-3.

91. Shedlofsky SI, Israel BC, McClain CJ, Hill DB, Blouin RA. Endotoxin administration to humans inhibits hepatic cytochrome P450-mediated drug metabolism. J Clin Invest. 1994;94:2209-14.

92. Satarug S, Lang MA, Yongvanit P, Sithithaworn P, Mairiang E, Mairiang P, et al. Induction of cytochrome P450 2A6 expression in humans by the carcinogenic parasite infection, opisthorchiasis viverrini. Cancer Epidemiol Biomarkers Prev. 1996;5:795-800.

93. Sotaniemi EA, Pelkonen O, Arranto AJ, Tapanainen P, Rautio A, Pasanen M. Diabetes and elimination of antipyrine in man: an analysis of 298 patients classified by type of diabetes, age, sex, duration of disease and liver involvement. Pharmacol Toxicol. 2002;90:155-60.

94. Williams SJ, Farrell GC. Inhibition of antipyrine metabolism by interferon. Br J Clin Pharmacol. 1986;22:610-2.

95. Levine M, Jones MW. Toxic reaction to phenytoin following a viral infection. Can Med Assoc J. 1983;128:1270-1.

96. Adedoyin A, Arns PA, Richards WO, Wilkinson GR, Branch RA. Selective effect of liver disease on the activities of specific metabolizing enzymes: investigation of cytochromes P450 2C19 and 2D6. Clin Pharmacol Ther. 1998;64:8-17.

97. Schulz J, Kluwe F, Mikus G, Michelet R, Kloft C. Novel insights into the complex pharmacokinetics of voriconazole: a review of its metabolism. Drug Metab Rev. 2019;51:247-65.

98. Dote S, Sawai M, Nozaki A, Naruhashi K, Kobayashi Y, Nakanishi H. A retrospective analysis of patient-specific factors on voriconazole clearance. J Pharm Health Care Sci. 2016;2:10.

99. Ventura MAE, Span LFR, van den Heuvel ER, Groothuis GMM, Alffenaar J-WC. Influence of inflammation on voriconazole metabolism. Antimicrob Agents Chemother. 2015;59:2942-3.

100. van Wanrooy MJP, Span LFR, Rodgers MGG, van den Heuvel ER, Uges DRA, van der Werf TS, et al. Inflammation is associated with voriconazole trough concentrations. Antimicrob Agents Chemother. 2014;58:7098-101.

101. Naito T, Yamada T, Mino Y, Kawakami J. Impact of inflammation and concomitant glucocorticoid administration on plasma 
concentration of triazole antifungals in immunocompromised patients. Clin Chim Acta. 2015;441:127-32.

102. Gautier-Veyret E, Truffot A, Bailly S, Fonrose X, Thiebaut-Bertrand A, Tonini J, et al. Inflammation is a potential risk factor of voriconazole overdose in hematological patients. Fundam Clin Pharmacol. 2019;33:232-8.

103. Yanni SB, Annaert PP, Augustijns P, Ibrahim JG, Benjamin DK, Thakker DR. In vitro hepatic metabolism explains higher clearance of voriconazole in children versus adults: role of CYP2C19 and flavin-containing monooxygenase 3. Drug Metab Dispos. 2010;38:25-31.

104. Lenoir C, Daali Y, Rollason V, Curtin F, Gloor Y, Bosilkovska $\mathrm{M}$, et al. Impact of acute inflammation on cytochromes P450 activity assessed by the Geneva cocktail. Clin Pharmacol Ther. 2021;109:1668-76.

105. Veringa A, Ter Avest M, Span LFR, van den Heuvel ER, Touw DJ, Zijlstra JG, et al. Voriconazole metabolism is influenced by severe inflammation: a prospective study. J Antimicrob Chemother. 2017;72:261-7.

106. Goktaş MT, Hatta F, Karaca O, Kalkisim S, Kilic L, Akdogan A, et al. Lower CYP2C9 activity in Turkish patients with Behçet's disease compared to healthy subjects: a down-regulation due to inflammation? Eur J Clin Pharmacol. 2015;71:1223-8. 